\title{
Type 2 Diabetes Mellitus Management and Body Mass Index: Experiences with Initiating Insulin Detemir in the $A_{1}$ chieve Study
}

\author{
Mohammed E. Khamseh • Vinay Prusty · Zafar Latif • \\ Guillermo Gonzalez-Galvez • Guillermo Dieuzeide • \\ Alexey Zilov
}

To view enhanced content go to www.diabetestherapy-open.com

Received: October 7, 2013 / Published online: January 30, 2014

(c) The Author(s) 2014. This article is published with open access at Springerlink.com

\section{ABSTRACT}

Introduction: This sub-analysis of the $\mathrm{A}_{1}$ chieve study aimed to examine the safety and efficacy of insulin detemir (IDet) initiation over 24 weeks in relation to baseline body mass index (BMI) in people with type 2 diabetes mellitus (T2DM).

Methods: $A_{1}$ chieve was a 24-week noninterventional study to assess the safety and efficacy of insulin analogs in routine practice. This sub-analysis included insulin-naïve

Trial registration number: NCT00869908.

Electronic supplementary material The online version of this article (doi:10.1007/s13300-014-0054-2) contains supplementary material, which is available to authorized users.

M. E. Khamseh ( $\square)$

Endocrine Research Center, Institute of Endocrinology and Metabolism, Iran University of Medical Sciences, Tehran, Iran e-mail: khamseh.m@iums.ac.ir

V. Prusty

Novo Nordisk Intl Operations, Zurich, Switzerland

Z. Latif

Bangladesh Institute of Research and Rehabilitation in Diabetes, Endocrine and Metabolic Disorders

(BIRDEM) Hospital, Dhaka, Bangladesh patients who initiated IDet therapy based on their physicians' decision. Patients were stratified according to baseline BMI (Group I, $<25.0 \mathrm{~kg} / \mathrm{m}^{2}$; Group II, 25.0 to $<30.0 \mathrm{~kg} / \mathrm{m}^{2}$; Group III, 30.0 to $<35.0 \mathrm{~kg} / \mathrm{m}^{2}$; Group IV $\geq 35.0 \mathrm{~kg} / \mathrm{m}^{2}$ ). Safety and efficacy variables were assessed over 24 weeks.

Results: Overall, 10,650 insulin-naïve patients were included (3,045 patients in Group I, 4,186 patients in Group II, 2,365 patients in Group III, and 1,054 patients in Group IV). Four serious adverse drug reactions (SADRs) were reported. From baseline to Week 24, there was no statistically significant difference in the proportion of patients reporting overall hypoglycemia in Group I (4.0\% vs. $4.4 \%)$, while a significant decrease in Group II $(4.8 \%$ vs. $4.0 \%, p=0.0335$ ) and significant increases

\section{G. Gonzalez-Galvez}

Instituto Jalisciense de Investigación en Diabetes

y Obesidad S. C., Guadalajara, Jal., Mexico

G. Dieuzeide

Centro de Atención Integral en Diabetes,

Endocrinología y Metabolismo (CAIDEM.R.E.), Buenos Aires, Argentina

\section{A. Zilov}

First Moscow State Medical University na I.M.

Sechenov, Moscow, Russia 
in Groups III and IV (3.3\% vs. $5.4 \%$ and $3.4 \%$ vs. $7.0 \%$, respectively, $p<0.001)$ were noted. The mean body weight increased from baseline to Week 24 in Group I $(60.7 \pm 8.4$ vs. $61.8 \pm 8.5 \mathrm{~kg}$ ) and reduced in Groups II, III, and IV $(74.5 \pm 9.2$ vs. $74.2 \pm 9.2 \mathrm{~kg}, 87.4 \pm 10.3$ vs. $\quad 86.0 \pm 9.8 \mathrm{~kg}$, and $102.2 \pm 14.3$ vs. $100.1 \pm 14.2 \mathrm{~kg}$, respectively; all $p<0.001$ ). Significant improvements were noted in glycemic parameters, systolic blood pressure, and lipids over 24 weeks, irrespective of baseline BMI status.

Conclusion: IDet therapy was associated with improved glycemic control and a low number of SADRs. Greater weight loss was observed with higher BMI.

Keywords: $\mathrm{A}_{1}$ chieve; Body mass index (BMI); Body weight; Hypoglycemia; Insulin detemir (IDet); Type 2 diabetes

\section{INTRODUCTION}

The main goal of type 2 diabetes mellitus (T2DM) management is to safely improve glycemic control [1]. The joint guidelines of the American Diabetes Association (ADA) and the European Association for the Study of Diabetes (EASD) recommend maintaining glycated hemoglobin $\mathrm{A}_{1 \mathrm{c}} \quad\left(\mathrm{HbA}_{1 \mathrm{c}}\right)$ levels $<7.0 \%$ ( $<53 \mathrm{mmol} / \mathrm{mol}$ ) for good glycemic control in patients with T2DM [2]. The guidelines also recommend a stepwise pathway for the initiation and subsequent intensification of oral glucose-lowering drugs (OGLDs) and insulin to combat the progressive nature of T2DM [2]. However, despite these recommendations, many T2DM patients continue to experience poor glycemic control in real-life settings [3].

Weight gain is a common consequence of intensified pharmacological therapy in T2DM [4]. Approximately $80 \%$ of patients with T2DM are either overweight [body mass index (BMI) $\left.25.0-29.9 \mathrm{~kg} / \mathrm{m}^{2}\right]$ or obese $\left(\mathrm{BMI}>30.0 \mathrm{~kg} / \mathrm{m}^{2}\right)$ [2]. Insulin is the most effective treatment for T2DM; however, possible weight gain resulting from insulin use is regarded as a major barrier to the initiation of insulin by many patients and physicians alike [5] and may be the cause of delayed insulin initiation in T2DM patients who are already overweight or obese [6]. It is, therefore, important to determine the potential impact of baseline BMI status on T2DM management strategies and patient outcomes in clinical practice.

The basal insulin analog, insulin detemir (IDet), is known to be safe and efficacious in the management of T2DM and induces less weight gain compared to treatment with other basal insulins, such as neutral protamine Hagedorn (NPH) insulin and insulin glargine [7]. IDet differs from endogenous insulin in that threonine has been deleted at position B30 and a myristic acid side chain is attached to the lysine residue at position B29 of the insulin molecule [8]. Due to these structural modifications, IDet molecules have a strong tendency to selfassociate and are highly bound to albumin in the subcutaneous depot, resulting in prolonged therapeutic action. A pooled analysis examining data from 900 T2DM patients treated with either IDet or NPH insulin in a basal-bolus regimen by Raslová et al. [9] demonstrated that patients on IDet therapy gained less weight compared to those on NPH insulin and the weight-limiting effect increased with baseline BMI.

The mechanism underlying the low weight gain noted with IDet therapy is currently unconfirmed [10]. It is possible that the low glucose variability associated with IDet therapy minimizes defensive snacking thereby limiting weight gain. It has also been hypothesized that IDet may have a positive effect on satiety signaling in the central nervous system [10], 
while another theory proposes that IDet may have a role in suppressing adipogenesis in the peripheral tissues due to its albumin-binding tendencies that promote greater exposure to hepatocytes than to peripheral tissues [10].

This sub-analysis of the $A_{1}$ chieve study [11] aimed to examine the safety and efficacy of IDet therapy in T2DM management in relation to baseline BMI in a heterogeneous cohort of insulin-naive patients. It is important to explore whether T2DM management practices are affected by baseline BMI status and also to determine whether the weight-limiting effects of IDet therapy in relation to baseline BMI are sustained in real-life clinical practice.

\section{MATERIALS AND METHODS}

\section{Study Design}

$\mathrm{A}_{1}$ chieve was a 24-week, open-label, multinational, non-interventional study to evaluate the clinical safety and efficacy of IDet (Levemir $^{\circledR}$, Novo Nordisk, Denmark), biphasic insulin aspart 30 (NovoMix 30 ${ }^{\circledR}$, Novo Nordisk, Denmark), and insulin aspart $\left(\right.$ NovoRapid $^{\circledR}$, Novo Nordisk, Denmark), alone or in combination, in the treatment of T2DM in routine clinical care [11]. Patients were recruited between January 2009 and June 2010 from 3,166 centers across 28 countries in 7 regions. The regions were China, East Asia (Indonesia, Korea, Malaysia, Philippines, Singapore, Taiwan), Latin America (Argentina, Mexico), Middle East + Gulf (Bahrain, Egypt, Iran, Jordan, Kuwait, Oman, Qatar, Saudi Arabia, Turkey, UAE, Yemen), North Africa (Algeria, Libya, Morocco, Tunisia), Russia, and South Asia (Bangladesh, India, Pakistan). This paper reports the safety and efficacy of IDet therapy in relation to baseline BMI in insulinnaïve patients in the overall $A_{1}$ chieve cohort.
The $\mathrm{A}_{1}$ chieve study design has been described in full previously by Home et al. [11]. Briefly, the decision to prescribe IDet was made by the physicians in routine clinical practice. IDet was commercially available and used in accordance with local regulatory standards. Due to the non-interventional approach of this study, there were no defined study procedures and all assessments were made by physicians during routine clinical visits. Data for analysis from the physicians' clinical notes and patients' recall and self-monitoring diary/ blood glucose meter were collected at baseline, Week 12 and Week 24 and transferred to a standard case report form (CRF). Concomitant OGLD use was also directed by the physicians.

\section{Patients}

Insulin-naïve patients initiating treatment with IDet within 4 weeks prior to the start of the study were included in this sub-analysis. Any patient who had been treated with the study insulins for over 4 weeks before the start of the study or who had a hypersensitivity to any of the insulins was excluded. Women who were pregnant, breastfeeding or intended to become pregnant within 6 months from the start of the study were also excluded. All procedures followed were in accordance with the ethical standards of the responsible committee on human experimentation (institutional and national of the participating countries) and with the Helsinki Declaration of 1975, as revised in 2008. Informed consent was obtained from all patients for being included in the study.

\section{Variables and Assessments}

The primary variable was the incidence of serious adverse drug reactions (SADRs), including major hypoglycemic events. 
Secondary variables included the change in the proportion of patients reporting hypoglycemic events in the last 4 weeks before baseline and before the final visit (Week 24), and the change from baseline to Week 24 in $\mathrm{HbA}_{1 \mathrm{c}}$, fasting plasma glucose (FPG), postprandial plasma glucose (PPPG), body weight, systolic blood pressure (SBP), lipids [total cholesterol, triglycerides, high-density lipoprotein (HDL) cholesterol, and low-density lipoprotein (LDL) cholesterol], and quality of life (QoL).

A hypoglycemic event was defined as an event with symptoms of hypoglycemia that resolved with oral carbohydrate intake, glucagon or intravenous glucose, or any symptomatic or asymptomatic plasma glucose measurement $<3.1 \mathrm{mmol} / \mathrm{L}$ or $56 \mathrm{mg} / \mathrm{dL}$.

Nocturnal hypoglycemic events were defined as individualized symptomatic events consistent with hypoglycemia, that occurred while the patient was asleep, between bedtime after the evening insulin injection and before getting up in the morning [if relevant; before morning determination of fasting plasma glucose (FPG) and before morning injection].

Major hypoglycemic events were defined as events with severe central nervous system symptoms consistent with hypoglycemia in which the patient was unable to treat himself/herself and had either plasma glucose $<3.1 \mathrm{mmol} / \mathrm{L}$ or $56 \mathrm{mg} / \mathrm{dL}$, or reversal of symptoms after either food intake or glucagon or intravenous glucose administration.

The EuroQol Visual Analogue Scale (EQ-VAS) was used to rate an individual's current healthrelated QoL state on a scale of 0 (worst score) to 100 (best score) based on responses to the EuroQol-5 Dimension questionnaire that evaluates mobility, anxiety/depression, pain/ discomfort, self-care and usual activity.

\section{Statistical Methods}

Patients were stratified by baseline BMI intervals (Group I, $\quad<25.0 \mathrm{~kg} / \mathrm{m}^{2}$; Group II, 25.0 to $<30.0 \mathrm{~kg} / \mathrm{m}^{2}$; Group III, 30.0 to $<35.0 \mathrm{~kg}$ / $\mathrm{m}^{2}$; and Group IV, $\geq 35.0 \mathrm{~kg} / \mathrm{m}^{2}$ ). Continuous and discrete variables were summarized using descriptive statistics (mean, SD) and frequency tables $(n, \%)$, respectively.

The change in the proportion of patients reporting at least one event of hypoglycemia in the 4 weeks before study visits was analyzed using McNemar's test. The change from baseline to Week 24 in $\mathrm{HbA}_{1 \mathrm{c}}$, FPG, PPPG, body weight, SBP, lipids, and QoL was analyzed using a paired $t$ test. Two-sided testing with a 5\% significance level was used $(\alpha=0.05)$.

Data analysis was performed by Novo Nordisk using SAS (Version 9.1.3).

\section{RESULTS}

\section{Patient Disposition and Baseline Demographics}

Overall, 12,078 insulin-naïve patients initiated IDet therapy; however, baseline BMI data was missing for 1,428 patients. Therefore, this subanalysis included 10,650 patients, who initiated IDet therapy. No other insulin therapy was administered during the 24-week study. Patient characteristics for the entire cohort, stratified by baseline BMI intervals, are presented in Table 1.

The mean baseline $\mathrm{HbA}_{1 \mathrm{c}}$ level was high across all four groups (Table 1). Over $97.0 \%$ of patients initiated IDet therapy to improve glycemic control across all groups. 
Table 1 Demographics and baseline characteristics by baseline BMI

\begin{tabular}{lllll}
\hline \multicolumn{5}{l}{ Baseline BMI group $\left(\mathbf{k g} / \mathbf{m}^{\mathbf{2}}\right)$} \\
\cline { 2 - 5 } & $<\mathbf{2 5 . 0}$ & $\mathbf{2 5 . 0}$ to $<\mathbf{3 0 . 0}$ & $\mathbf{3 0 . 0}$ to $<\mathbf{3 5 . 0}$ & $\mathbf{2 3 5 . 0}$ \\
\hline$N$ & 3,045 & 4,186 & 2,365 & 1,054 \\
Male/female (\%) & $57.1 / 42.9$ & $60.6 / 39.4$ & $48.9 / 51.1$ & $39.6 / 60.4$ \\
Age (years) & $55.6 \pm 12.2$ & $53.5 \pm 11.1$ & $52.7 \pm 10.4$ & $52.6 \pm 10.1$ \\
Duration of T2DM (years) & $8.1 \pm 6.3$ & $7.5 \pm 5.3$ & $7.5 \pm 4.8$ & $7.7 \pm 4.8$ \\
Duration on OGLDs (years) & $7.1 \pm 5.9$ & $6.8 \pm 5.2$ & $6.8 \pm 4.7$ & $7.0 \pm 4.6$ \\
$\mathrm{HbA}_{\mathrm{lc}}(\% / \mathrm{mmol} / \mathrm{mol})$ & $9.6 \pm 1.8 / 81 \pm 20$ & $9.4 \pm 1.6 / 79 \pm 17$ & $9.4 \pm 1.4 / 79 \pm 15$ & $9.7 \pm 1.6 / 83 \pm 17$ \\
BMI $\left(\mathrm{kg} / \mathrm{m}^{2}\right)$ & $22.5 \pm 2.0$ & $27.4 \pm 1.4$ & $32.2 \pm 1.4$ & $38.8 \pm 3.6$ \\
Body weight $(\mathrm{kg})$ & $60.7 \pm 8.4$ & $74.5 \pm 9.2$ & $87.4 \pm 10.3$ & $102.2 \pm 14.3$ \\
\hline
\end{tabular}

Data are mean $\pm \mathrm{SD}$ or as stated

$B M I$ body mass index, $H b A_{1 c}$ glycated hemoglobin A1c, $O G L D$ oral glucose-lowering drug, $T 2 D M$ type 2 diabetes mellitus

The most commonly used OGLDs in each group at pre-study (prior to study enrolment), baseline and Week 24 are presented in Table 2 . At pre-study, baseline and Week 24, a higher proportion of patients with a higher baseline BMI were on more than two OGLDs.

\section{Insulin Dose and Dosing Frequency}

The mean total daily insulin dose, dose by body weight and dosing frequency are presented in Table 3.

At baseline, the mean insulin dose by weight was lowest in Group IV $(0.20 \pm 0.12 \mathrm{U} / \mathrm{kg})$. At Week 24 , the mean insulin dose by weight was observed to be similar across the four groups (Group I, $0.36 \pm 0.18$ U/kg; Group II, $0.35 \pm 0.19$ $\mathrm{U} / \mathrm{kg}$; Group III, $0.35 \pm 0.18 \mathrm{U} / \mathrm{kg}$; Group IV, $0.35 \pm 0.18 \mathrm{U} / \mathrm{kg}$ ), while the total daily insulin dose was noted to increase with increasing BMI (Group I, $21.8 \pm 11.4$ U/day; Group II, $25.9 \pm 14.2$ U/day; Group III, $29.9 \pm 15.6$ U/day; Group IV, $34.8 \pm 18.9$ U/day).

The majority of patients $(>75.0 \%)$ in all four groups followed once-daily dosing at baseline and Week 24.

\section{SADRs and Hypoglycemia}

A total of 4 SADRs, all considered probably related to IDet therapy, were reported: 1 event of hyperglycemia in Group I, and 2 events of hypoglycemia and 1 event of hyperglycemia in Group II.

In Group I, there was no statistically significant difference in the proportion of patients reporting overall hypoglycemia from the 4 weeks preceding baseline to the 4 weeks preceding the final visit $(4.0 \%$ vs. $4.4 \%$, Table 4). In Group II, a significant decrease was noted in the proportion of patients reporting overall hypoglycemia from the 4 weeks preceding baseline to the 4 weeks preceding the final visit $(4.8 \%$ vs. $4.0 \%$, $p=0.0335)$, while in Groups III and IV, significant increases were noted in the proportion of patients reporting overall hypoglycemia from the 4 weeks preceding baseline to the 4 weeks preceding the final visit $(3.3 \%$ vs. $5.4 \%$ and $3.4 \%$ vs. $7.0 \%$, respectively, both $p<0.001$ ).

During the 4 weeks preceding the final visit, only 1 event of major hypoglycemia was 
Table 2 Oral glucose-lowering drugs used at pre-study, baseline and Week 24

\begin{tabular}{|c|c|c|c|c|c|}
\hline \multirow[t]{2}{*}{ Time point } & \multirow[t]{2}{*}{ OGLDs, $n(\%)$} & \multicolumn{4}{|c|}{ Baseline BMI group $\left(\mathrm{kg} / \mathrm{m}^{2}\right)$} \\
\hline & & $<25.0$ & 25.0 to $<30.0$ & 30.0 to $<35.0$ & $\geq 35.0$ \\
\hline \multirow[t]{7}{*}{ Pre-study } & $n$ & 2,794 & 3,991 & 2,272 & 1,022 \\
\hline & Metformin & $2,128(76.2)$ & $3,426(85.8)$ & $2,044(90.0)$ & $937(91.7)$ \\
\hline & Sulfonylureas & $2,238(80.1)$ & $3,374(84.5)$ & $2,014(88.6)$ & $926(90.6)$ \\
\hline & Thiazolidinediones & $483(17.3)$ & $864(21.6)$ & $625(27.5)$ & $312(30.5)$ \\
\hline & $1 \mathrm{OGLD}^{\mathrm{a}}$ & $690(24.7)$ & $598(15.0)$ & $234(10.3)$ & $90(8.8)$ \\
\hline & $2 \mathrm{OGLDs}^{\mathrm{a}}$ & $1,484(53.1)$ & $2,362(59.2)$ & $1,310(57.7)$ & $563(55.1)$ \\
\hline & $>2$ OGLDs $^{a}$ & $620(22.2)$ & $1,031(25.8)$ & $728(32.0)$ & $369(36.1)$ \\
\hline \multirow[t]{7}{*}{ Baseline } & $n$ & 2,621 & 3,850 & 2,231 & 1,004 \\
\hline & Metformin & $1,854(70.7)$ & $3,128(81.2)$ & $1,940(87.0)$ & $909(90.5)$ \\
\hline & Sulfonylureas & $1,599(61.0)$ & $2,496(64.8)$ & $1,651(74.0)$ & $762(75.9)$ \\
\hline & Thiazolidinediones & $292(11.1)$ & $465(12.1)$ & $269(12.1)$ & $171(17.0)$ \\
\hline & $1 \mathrm{OGLD}^{\mathrm{a}}$ & $1,209(46.1)$ & $1,427(37.1)$ & $596(26.7)$ & $212(21.1)$ \\
\hline & $2 \mathrm{OGLDs}^{\mathrm{a}}$ & $1,156(44.1)$ & $2,009(52.2)$ & $1,358(60.9)$ & $605(60.3)$ \\
\hline & $>2$ OGLDs $^{a}$ & $256(9.8)$ & $414(10.8)$ & $277(12.4)$ & $187(18.6)$ \\
\hline \multirow[t]{7}{*}{ Week 24} & $n$ & 2,252 & 3,427 & 2,072 & 918 \\
\hline & Metformin & $1,706(75.8)$ & $2,845(83.0)$ & $1,860(89.8)$ & $856(93.2)$ \\
\hline & Sulfonylureas & $1,300(57.7)$ & $2,155(62.9)$ & $1,441(69.5)$ & $654(71.2)$ \\
\hline & Thiazolidinediones & $203(9.0)$ & $339(9.9)$ & $244(11.8)$ & $148(16.1)$ \\
\hline & $1 \mathrm{OGLD}^{\mathrm{a}}$ & $1,052(46.7)$ & $1,325(38.7)$ & $553(26.7)$ & $205(22.3)$ \\
\hline & $2 \mathrm{OGLDs}^{\mathrm{a}}$ & $1,004(44.6)$ & $1,748(51.0)$ & $1,238(59.7)$ & $528(57.5)$ \\
\hline & $>2 \mathrm{OGLDs}^{\mathrm{a}}$ & $196(8.7)$ & $354(10.3)$ & $281(13.6)$ & $185(20.2)$ \\
\hline
\end{tabular}

'Pre-study' is defined as the period prior to study enrolment. Data are represented as $n$ (\%), or as stated $B M I$ body mass index, $O G L D$ oral glucose-lowering drug, $n$ the number of patients that were on OGLDs

a OGLDs used also included exenatide, DPP-4 inhibitors, glucosidase inhibitors and glinides

reported in Group IV. Incidence rates of minor and nocturnal hypoglycemia were observed to be directly proportional to BMI in the 4 weeks preceding the final visit (Table 4).

\section{Glycemic Control, Body Weight and SBP}

Significant reductions in $\mathrm{HbA}_{1 \mathrm{c}}$, FPG and PPPG were observed in all four groups after 24 weeks
(Table 5). At Week 24, the mean reductions in $\mathrm{HbA}_{1 \mathrm{c}}$, FPG and PPPG were similar across groups.

More patients met the $\mathrm{HbA}_{1 \mathrm{c}}$ target of $<7.0 \%$ $(<53 \mathrm{mmol} / \mathrm{mol})$ at Week 24 compared to baseline in all four groups [Group I, 75 (3.1\%) at baseline vs. $628(30.8 \%)$ at Week 24; Group II, $66(1.8 \%)$ at baseline vs. 1,086 (32.9\%) at Week 24; Group III, $32(1.5 \%)$ at baseline vs. 701 
Table 3 Insulin dose and dosing frequency at baseline and Week 24 by baseline BMI

\begin{tabular}{|c|c|c|c|c|}
\hline & \multicolumn{4}{|c|}{ Baseline BMI group $\left(\mathrm{kg} / \mathrm{m}^{2}\right)$} \\
\hline & $<25.0$ & 25.0 to $<30.0$ & 30.0 to $<35.0$ & $\geq 35.0$ \\
\hline \multicolumn{5}{|c|}{ Insulin dose (U/day) } \\
\hline$n$ & 3,045 & 4,186 & 2,365 & 1,054 \\
\hline Baseline $^{a}$ & $15.8 \pm 7.8$ & $18.1 \pm 9.7$ & $18.9 \pm 10.8$ & $20.8 \pm 12.8$ \\
\hline Week $24^{\mathrm{a}}$ & $21.8 \pm 11.4$ & $25.9 \pm 14.2$ & $29.9 \pm 15.6$ & $34.8 \pm 18.9$ \\
\hline \multicolumn{5}{|c|}{ Insulin dose $(\mathrm{U} / \mathrm{kg})$} \\
\hline$n$ & 3,045 & 4,186 & 2,365 & 1,054 \\
\hline Baseline $^{a}$ & $0.27 \pm 0.13$ & $0.25 \pm 0.13$ & $0.22 \pm 0.12$ & $0.20 \pm 0.12$ \\
\hline Week $24^{\mathrm{a}}$ & $0.36 \pm 0.18$ & $0.35 \pm 0.19$ & $0.35 \pm 0.18$ & $0.35 \pm 0.18$ \\
\hline \multicolumn{5}{|c|}{ Dosing frequency at baseline, $n(\%)$} \\
\hline$n$ & 3,045 & 4,186 & 2,365 & 1,054 \\
\hline Once daily ${ }^{\mathrm{b}}$ & $2,815(92.4)$ & $3,687(88.1)$ & $2,205(93.2)$ & $962(91.3)$ \\
\hline Twice daily ${ }^{\mathrm{b}}$ & $222(7.3)$ & $492(11.8)$ & $157(6.6)$ & $91(8.6)$ \\
\hline Thrice daily ${ }^{\mathrm{b}}$ & $7(0.2)$ & $6(0.1)$ & $3(0.1)$ & $1(0.1)$ \\
\hline$>$ Thrice daily ${ }^{\mathrm{b}}$ & $1(0.0)$ & $1(0.0)$ & - & - \\
\hline \multicolumn{5}{|c|}{ Dosing frequency at Week 24, $n(\%)$} \\
\hline$n$ & 2,580 & 3,691 & 2,176 & 968 \\
\hline Once daily ${ }^{\mathrm{b}}$ & $2,160(83.7)$ & $2,841(77.0)$ & $1,705(78.4)$ & $733(75.7)$ \\
\hline Twice daily $^{\mathrm{b}}$ & $337(13.1)$ & $729(19.8)$ & $383(17.6)$ & $180(18.6)$ \\
\hline Thrice daily $^{\mathrm{b}}$ & $28(1.1)$ & $35(0.9)$ & $37(1.7)$ & $23(2.4)$ \\
\hline$>$ Thrice daily ${ }^{\mathrm{b}}$ & $55(2.1)$ & $86(2.3)$ & $51(2.3)$ & $32(3.3)$ \\
\hline
\end{tabular}

The mean total daily IDet dose at baseline and Week 24 is presented in units of $U /$ day and $U / \mathrm{kg}$ for each group. Dosing frequency of IDet at baseline and Week 24 is summarized and presented as once daily, twice daily, thrice daily and >thrice daily. As this was a non-interventional study, data collection was based on the number of patients that reported dose details at baseline and Week 24

$B M I$ body mass index

${ }^{a}$ Data are represented as mean $\pm S D$

b Data are represented as $n(\%)$

(34.2\%) at Week 24; Group IV, $14(1.4 \%)$ at baseline vs. $292(31.4 \%)$ at Week 24].

After 24 weeks, a significant increase in body weight was noted in Group I $(1.0 \pm 3.2 \mathrm{~kg})$, while significant decreases were observed in the remaining three groups (all $p<0.001$, Table 5). Greater weight reductions were observed with high BMI (Group II, $-0.3 \pm 3.5 \mathrm{~kg}$; Group III, $-1.4 \pm$ $4.3 \mathrm{~kg}$; Group IV, $-2.2 \pm 5.0 \mathrm{~kg}$ ).

The mean SBP improved markedly across all groups (all $p<0.001$, Table 5). 


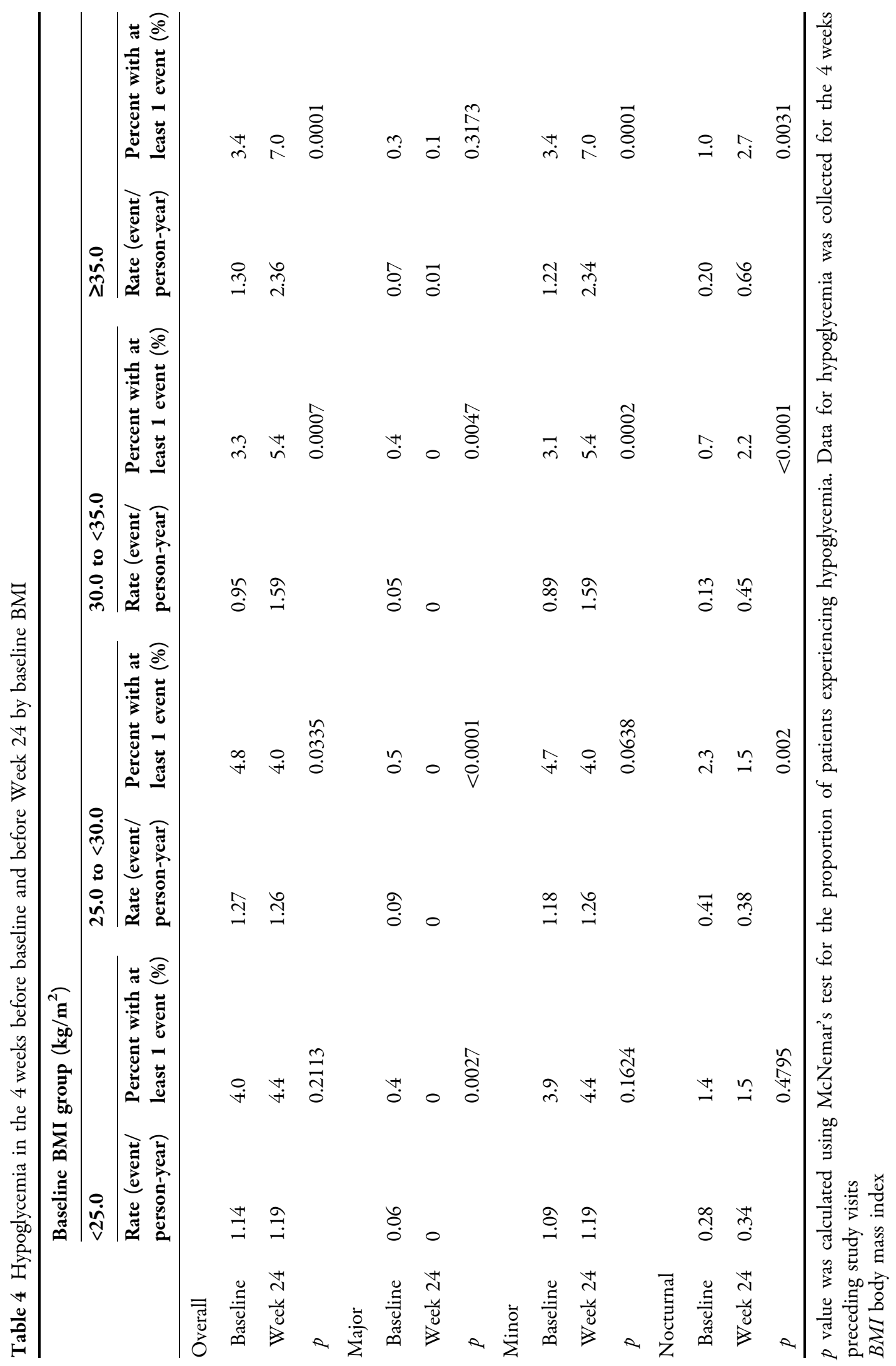


Table 5 Glycemic parameters, body weight and SBP at baseline and Week 24 by baseline BMI

\begin{tabular}{|c|c|c|c|c|}
\hline & \multicolumn{4}{|c|}{ Baseline BMI group $\left(\mathrm{kg} / \mathrm{m}^{2}\right)$} \\
\hline & $<25.0$ & 25.0 to $<30.0$ & 30.0 to $<35.0$ & $\geq 35.0$ \\
\hline \multicolumn{5}{|c|}{$\mathrm{HbA}_{1 \mathrm{c}}(\% / \mathrm{mmol} / \mathrm{mol})$} \\
\hline$n$ & 1,814 & 3,055 & 1,936 & 871 \\
\hline Baseline & $9.6 \pm 1.8 / 81 \pm 20$ & $9.4 \pm 1.6 / 79 \pm 17$ & $9.4 \pm 1.4 / 79 \pm 15$ & $9.7 \pm 1.6 / 83 \pm 17$ \\
\hline Week 24 & $7.6 \pm 1.3 / 60 \pm 14$ & $7.3 \pm 1.0 / 56 \pm 11$ & $7.3 \pm 1.0 / 56 \pm 11$ & $7.5 \pm 1.1 / 59 \pm 12$ \\
\hline Change, $p$ & $\begin{array}{l}-2.1 \pm 1.7 /-23 \pm 19 \\
\quad<0.001\end{array}$ & $\begin{array}{l}-2.1 \pm 1.6 /-23 \pm 17 \\
<0.001\end{array}$ & $\begin{array}{l}-2.1 \pm 1.4 /-23 \pm 15 \\
<0.001\end{array}$ & $\begin{array}{l}-2.2 \pm 1.5 /-24 \pm 16 \\
<0.001\end{array}$ \\
\hline \multicolumn{5}{|c|}{$\mathrm{FPG}(\mathrm{mg} / \mathrm{dL})$} \\
\hline$n$ & 1,992 & 3,121 & 1,916 & 825 \\
\hline Baseline & $205.7 \pm 63.9$ & $201.1 \pm 56.7$ & $196.2 \pm 53.7$ & $202.0 \pm 53.4$ \\
\hline Week 24 & $125.6 \pm 35.6$ & $126.7 \pm 33.1$ & $123.5 \pm 31.7$ & $127.5 \pm 34.7$ \\
\hline Change, $p$ & $-80.0 \pm 65.4,<0.001$ & $-74.4 \pm 55.6,<0.001$ & $-72.7 \pm 51.7,<0.001$ & $-74.5 \pm 53.5,<0.001$ \\
\hline \multicolumn{5}{|c|}{ PPPG (mg/dL) } \\
\hline$n$ & 1,281 & 2,148 & 1,342 & 597 \\
\hline Baseline & $271.7 \pm 77.6$ & $271.9 \pm 73.1$ & $260.8 \pm 71.7$ & $269.0 \pm 74.5$ \\
\hline Week 24 & $173.4 \pm 53.7$ & $170.6 \pm 46.8$ & $164.5 \pm 44.4$ & $170.0 \pm 48.4$ \\
\hline Change, $p$ & $-98.3 \pm 80.9,<0.001$ & $-101.3 \pm 73.9,<0.001$ & $-96.3 \pm 69.6,<0.001$ & $-99.0 \pm 72.3,<0.001$ \\
\hline \multicolumn{5}{|c|}{ Body weight $(\mathrm{kg})$} \\
\hline$n$ & 2,373 & 3,442 & 2,044 & 896 \\
\hline Baseline & $60.7 \pm 8.4$ & $74.5 \pm 9.2$ & $87.4 \pm 10.3$ & $102.2 \pm 14.3$ \\
\hline Week 24 & $61.8 \pm 8.5$ & $74.2 \pm 9.2$ & $86.0 \pm 9.8$ & $100.1 \pm 14.2$ \\
\hline Change, $p$ & $1.0 \pm 3.2,<0.001$ & $-0.3 \pm 3.5,<0.001$ & $-1.4 \pm 4.3,<0.001$ & $-2.2 \pm 5.0,<0.001$ \\
\hline \multicolumn{5}{|c|}{$\mathrm{SBP}(\mathrm{mmHg})$} \\
\hline$n$ & 2,201 & 3,116 & 2,040 & 917 \\
\hline Baseline & $129.6 \pm 17.9$ & $133.3 \pm 16.2$ & $134.9 \pm 15.5$ & $136.8 \pm 15.9$ \\
\hline Week 24 & $125.5 \pm 14.0$ & $127.9 \pm 17.2$ & $128.7 \pm 12.9$ & $130.5 \pm 15.0$ \\
\hline Change, $p$ & $-4.2 \pm 17.6,<0.001$ & $-5.4 \pm 19.3,<0.001$ & $-6.2 \pm 15.0,<0.001$ & $-6.2 \pm 16.7,<0.001$ \\
\hline
\end{tabular}

All data are mean $\pm S D$ or as stated

$B M I$ body mass index, $F P G$ fasting plasma glucose, $H b A_{1 c}$ glycated hemoglobin A1c, $P P P G$ postprandial plasma glucose, $S B P$ systolic blood pressure

\section{Lipid Profile}

Baseline lipid levels appeared to be similar across the four groups. Significant reductions were noted in total cholesterol, triglyceride and LDL cholesterol levels across all groups from baseline to Week 24 (all $p<0.001$, Table 6). There was no significant change in HDL 
Table 6 Lipid profile at baseline and Week 24 by baseline BMI

\begin{tabular}{|c|c|c|c|c|}
\hline & \multicolumn{4}{|c|}{ Baseline BMI group $\left(\mathrm{kg} / \mathrm{m}^{2}\right)$} \\
\hline & $<25.0$ & 25.0 to $<30.0$ & 30.0 to $<35.0$ & $\geq 35.0$ \\
\hline \multicolumn{5}{|c|}{ Total cholesterol $(\mathrm{mmol} / \mathrm{L})$} \\
\hline$n$ & 805 & 1,455 & 1,320 & 625 \\
\hline Baseline & $5.1 \pm 1.3$ & $5.3 \pm 1.2$ & $5.4 \pm 1.2$ & $5.4 \pm 1.2$ \\
\hline Week 24 & $4.7 \pm 0.9$ & $4.8 \pm 0.9$ & $4.8 \pm 1.0$ & $4.9 \pm 0.9$ \\
\hline Change, $p$ & $-0.4 \pm 1.2,<0.001$ & $-0.6 \pm 1.1,<0.001$ & $-0.6 \pm 1.1,<0.001$ & $-0.5 \pm 1.0,<0.001$ \\
\hline \multicolumn{5}{|c|}{ Triglycerides $(\mathrm{mmol} / \mathrm{L})$} \\
\hline$n$ & 760 & 1,403 & 1,210 & 585 \\
\hline Baseline & $1.9 \pm 1.1$ & $2.1 \pm 1.1$ & $2.1 \pm 1.0$ & $2.1 \pm 1.0$ \\
\hline Week 24 & $1.6 \pm 0.8$ & $1.7 \pm 0.7$ & $1.8 \pm 0.6$ & $1.7 \pm 0.6$ \\
\hline Change, $p$ & $-0.3 \pm 1.0,<0.001$ & $-0.4 \pm 0.9,<0.001$ & $-0.4 \pm 0.8,<0.001$ & $-0.4 \pm 0.8,<0.001$ \\
\hline \multicolumn{5}{|c|}{ HDL cholesterol $(\mathrm{mmol} / \mathrm{L})$} \\
\hline$n$ & 614 & 1,115 & 993 & 478 \\
\hline Baseline & $1.2 \pm 0.4$ & $1.1 \pm 0.4$ & $1.1 \pm 0.4$ & $1.1 \pm 0.3$ \\
\hline Week 24 & $1.2 \pm 0.4$ & $1.2 \pm 0.3$ & $1.2 \pm 0.4$ & $1.2 \pm 0.3$ \\
\hline Change, $p$ & $0.0 \pm 0.4,0.167$ & $0.0 \pm 0.4,<0.001$ & $0.1 \pm 0.3,<0.001$ & $0.1 \pm 0.3,<0.001$ \\
\hline \multicolumn{5}{|c|}{ LDL cholesterol $(\mathrm{mmol} / \mathrm{L})$} \\
\hline$n$ & 623 & 1,129 & 995 & 491 \\
\hline Baseline & $3.0 \pm 1.0$ & $3.1 \pm 1.0$ & $3.2 \pm 1.1$ & $3.1 \pm 0.9$ \\
\hline Week 24 & $2.7 \pm 0.8$ & $2.7 \pm 0.9$ & $2.7 \pm 0.8$ & $2.7 \pm 0.8$ \\
\hline Change, $p$ & $-0.3 \pm 1.0,<0.001$ & $-0.4 \pm 1.1,<0.001$ & $-0.5 \pm 1.0,<0.001$ & $-0.4 \pm 0.9,<0.001$ \\
\hline
\end{tabular}

All data are mean $\pm S D$ or as stated. As this was a non-interventional study, data collection was based on the number of patients with lipid measurements at baseline and Week 24

$B M I$ body mass index, $H D L$ high-density lipoprotein, $L D L$ low-density lipoprotein

cholesterol in Group I, while significant increases were noted in the remaining three groups (all $p<0.001$, Table 6).

\section{Quality of Life}

The mean EQ-5D VAS scores improved significantly from baseline to Week 24 for all groups (Group I, $63.4 \pm 16.1$ points vs. $77.1 \pm 12.1$ points; Group II, $60.7 \pm 17.5$ points vs. $77.7 \pm 12.3$ points; Group III,
$60.2 \pm 17.3$ points vs. $77.4 \pm 12.0$ points; Group IV, $61.3 \pm 17.7$ points vs. $75.7 \pm 12.5$ points; all $p<0.001)$.

\section{DISCUSSION}

This sub-analysis of the $\mathrm{A}_{1}$ chieve study demonstrated the safety and efficacy of IDet therapy, irrespective of baseline BMI status, in a cohort of insulin-naïve patients. The initiation of IDet therapy was well-tolerated in all patient 
subgroups, stratified by baseline BMI intervals, with only four SADRs reported in the entire cohort of 10,650 patients.

Body weight is known to impact the progression of T2DM with weight gain leading to increased insulin resistance [12]. Weight loss is the chief recommendation for overweight and obese patients with T2DM according to the 2013 ADA Standards of Medical Care [13], and this is also endorsed by the International Diabetes Federation global guidelines for T2DM [14]. Meneghini et al. [1] suggested that T2DM patients with an $\mathrm{HbA}_{1 \mathrm{c}}$ level close to the ADA target of $<7.0 \%(<53 \mathrm{mmol} / \mathrm{mol})$ might benefit from glucose-lowering therapies that minimize weight gain. However, for patients with very poor glycemic control $\left[\mathrm{HbA}_{1 \mathrm{c}}\right.$ levels $>8.0 \% \quad(>64 \mathrm{mmol} / \mathrm{mol})]$, the first priority must be to improve glycemic control, followed by modulating weight gain [15].

At baseline, all patient subgroups had mean $\mathrm{HbA}_{1 \mathrm{c}}$ levels $>9.0 \%$ ( $\left.>75 \mathrm{mmol} / \mathrm{mol}\right)$ with more than half of the patients $(>50.0 \%)$ in all subgroups taking 2 OGLDs (commonly metformin and sulfonylurea). High BMI levels did not appear to be related to worsened glycemic control, concordant with the findings from the SOLVE study on the initiation of IDet therapy [6]. All subgroups had a mean duration of T2DM of approximately 8.0 years and a mean duration on OGLDs of approximately 7.0 years. These findings point to a general lack of application of international recommendations for timely therapeutic intensification in actual clinical practice. However, delayed therapy intensification did not appear to be linked with high baseline BMI.

It is known that patients with high levels of $\mathrm{HbA}_{1 \mathrm{c}}$ prior to the initiation of insulin attain the most clinically significant improvements in glycemic control [6]. In the current subanalysis, all patient subgroups experienced a significant reduction in mean $\mathrm{HbA}_{1 \mathrm{c}}$ levels by approximately $-2.1 \%(-23 \mathrm{mmol} / \mathrm{mol})$.

The mean FPG and PPPG levels also improved significantly following the start of IDet therapy. The ADA-EASD guidelines recommend maintaining FPG levels at $<130 \mathrm{mg} / \mathrm{dL}$ and PPPG at $<180 \mathrm{mg} / \mathrm{dL}$ to reduce the risk of micro- and macrovascular complications [2]. Despite high mean baseline levels of FPG and PPPG of $>195 \mathrm{mg} / \mathrm{dL}$ and $>260 \mathrm{mg} / \mathrm{dL}$, respectively, the mean values at Week 24 met the recommended targets in all patient subgroups. Also, the number of patients meeting the $\mathrm{HbA}_{1 \mathrm{c}}$ target level of $<7.0 \%$ $(<53 \mathrm{mmol} / \mathrm{mol})$ appeared to increase at Week 24 compared to baseline.

A significant decrease from the 4 weeks preceding baseline to the 4 weeks preceding the final visit was noted in the proportion of patients reporting overall hypoglycemia in Group I $\left(25.0\right.$ to $\left.<30.0 \mathrm{~kg} / \mathrm{m}^{2}\right)$. A significant increase from baseline to Week 24 was witnessed in the proportion of patients reporting overall hypoglycemia in Groups III and IV ( 30.0 to $<35.0 \mathrm{~kg} / \mathrm{m}^{2}$, and $\geq 35.0 \mathrm{~kg} / \mathrm{m}^{2}$ ); however, the overall incidence of hypoglycemia at Week 24 remained low (1.59 and 2.36 events per patient-year, respectively). These results are in keeping with the known safety profile of IDet [7]. The incidence of minor and nocturnal hypoglycemic events also remained low at the end of the study, while only 1 event of major hypoglycemia was reported at Week 24 in a patient from Group IV $\left(\geq 35.0 \mathrm{~kg} / \mathrm{m}^{2}\right)$.

IDet is known to exert a beneficial effect on weight gain and the findings from this study are in accordance with previously reported results from clinical trials [16, 17]. A modest, statistically significant increase in mean body weight $(1.0 \pm 3.2 \mathrm{~kg})$ was noted in Group I $\left(<25.0 \mathrm{~kg} / \mathrm{m}^{2}\right)$ after 24 weeks. The mean body weight was observed to decrease 
significantly for patients in the overweight and obese BMI groups and greater weight reductions were observed with higher BMI (25.0 to $<30.0 \mathrm{~kg} / \mathrm{m}^{2}, \quad-0.3 \pm 3.5 \mathrm{~kg} ; \quad 30.0$ to $<35.0 \mathrm{~kg} / \mathrm{m}^{2}, \quad-1.4 \pm 4.3 \mathrm{~kg}$; $\geq 35.0 \mathrm{~kg} / \mathrm{m}^{2}$, $-2.2 \pm 5.0 \mathrm{~kg}$ ) at Week 24. Results from the TITRATE study, in which IDet was added to OGLD regimens, also indicated that changes in body weight from baseline after initiating IDet treatment were related to baseline BMI [18]. In two clinical trials, patients with higher baseline BMI gained less weight with IDet therapy [16, 19] and this finding was also noted in a subgroup analysis of the large, observational PREDICTIVE study on IDet therapy [20].

High blood pressure and abnormal lipid levels are common co-morbidities in T2DM patients with poor glycemic control [21]. The significant improvement in SBP levels, especially in the overweight and obese BMI groups $\left(25.0\right.$ to $<30.0 \mathrm{~kg} / \mathrm{m}^{2}, \quad 30.0$ to $<35.0 \mathrm{~kg} / \mathrm{m}^{2}$, and $\geq 35.0 \mathrm{~kg} / \mathrm{m}^{2}$ ) by an average of $5-6 \mathrm{mmHg}$, is particularly noteworthy in light of a recent meta-analysis by Bangalore et al. [22], wherein a reduction of SBP below $135 \mathrm{mmHg}$ was found to be associated with a $10 \%$ reduction in all-cause mortality and a $17 \%$ reduction in the risk of stroke.

By Week 24, significant reductions in total cholesterol, triglyceride and LDL cholesterol were also seen across all patient subgroups. The mean HDL cholesterol levels remained stable in all subgroups and increased significantly for patients in the overweight and obese BMI groups (25.0 to $<30.0 \mathrm{~kg} / \mathrm{m}^{2}, 30.0$ to $<35.0 \mathrm{~kg} / \mathrm{m}^{2}$, and $\geq 35.0 \mathrm{~kg} / \mathrm{m}^{2}$ ) by Week 24 .

Patients with T2DM often avoid the initiation of insulin due to perceptions that life will become more restricted [23]. Also, fear of needles and the inconvenience of taking daily insulin injections have been cited as major blocks to the initiation of insulin by many patients. However, in this sub-analysis, the mean QoL improved significantly across all patient subgroups. It is possible that the patients may have experienced a sense of wellbeing associated with the reductions in glycemic endpoints and the general improvements seen in body weight in the higher BMI groups, and lipid and SBP levels, together with the low incidence of hypoglycemia.

This study had certain limitations due to its non-interventional nature, including the absence of a control group and the possible lack of standardization of procedures across sites. Data on hypoglycemic events occurring in the preceding 4 weeks were captured retrospectively at study visits and could have been subjected to recall bias. Furthermore, lifestyle and dietary information were not tracked, so it is not possible to determine whether any advice from the physicians or changes initiated by the patients may have affected the treatment outcomes.

Nevertheless, this study offered an opportunity to investigate T2DM management practices in a heterogeneous cohort of patients with varying BMI status at baseline and the results were generally concordant with the wellknown safety and efficacy of IDet therapy. In conclusion, the results observed in this cohort are encouraging as IDet therapy was associated with significant improvements in glycemic parameters, irrespective of baseline BMI status, and also induced weight loss in overweight and obese patients with T2DM.

\section{ACKNOWLEDGMENTS}

Sponsorship and article processing charges for this were funded by Novo Nordisk A/S, Denmark. The sponsor took part in the 
development of the protocol, the process of data collection and analysis, funding of medical writing services, and in reviewing the manuscript, but not in participant selection, choice of therapies (study or otherwise), provision of therapies including insulin or continuing clinical management of the participants. The authors would like to thank all participants who provided data, and all investigators involved in the $A_{1}$ chieve study. The authors would like to thank Chunduo Shen of Novo Nordisk for providing statistical analysis. The authors would also like to thank Anjali Philip of Cognizant Technology Solutions for writing assistance, funded by Novo Nordisk. Vinay Prusty is the guarantor for this article and takes responsibility for the integrity of the work as a whole.

Conflict of interest. Mohammad Khamseh participated in a national multicentre clinical trial sponsored by Novo Nordisk and has served on an advisory panel for Novo Nordisk. Vinay Prusty is employed by Novo Nordisk A/S. Zafar Latif has conducted research and received honoraria for the conduction of research and delivering lectures from Novo Nordisk, Sanofi, Eli Lilly, Novartis and Servier. Guillermo Gonzalez-Galvez is an advisory board member for MSD, Sanofi, Novo Nordisk, Janssen, Boehringer, Bristol Myer Squibb and AstraZeneca. Guillermo Dieuzeide has served as an advisor for Novo Nordisk, Aventis, Bristol Myer Squibb/AstraZeneca; participated as principal investigator in research sponsored by Novo Nordisk, Aventis, Bristol Myer Squibb/ AstraZeneca and Takeda; and received grants from Novo Nordisk, Aventis, Roche, Lilly, Montpellier and Beta. Alexei Zilov has served as a lecturer for Sanofi, Novartis, Novo Nordisk, Takeda, and AstraZeneca.
Compliance with ethics guidelines. All procedures followed were in accordance with the ethical standards of the responsible committee on human experimentation (institutional and national) and with the Helsinki Declaration of 1975, as revised in 2000 and 2008. Informed consent was obtained from all patients for being included in the study.

Open Access. This article is distributed under the terms of the Creative Commons Attribution Noncommercial License which permits any noncommercial use, distribution, and reproduction in any medium, provided the original author(s) and the source are credited.

\section{REFERENCES}

1. Meneghini LF, Orozco-Beltran D, Khunti K, et al. Weight beneficial treatments for type 2 diabetes. J Clin Endocrinol Metab. 2011;96:3337-53.

2. Inzucchi SE, Bergenstal RM, Buse JB, American Diabetes Association (ADA), European Association for the Study of Diabetes (EASD), et al. Management of hyperglycaemia in type 2 diabetes: a patientcentered approach. Position statement of the American Diabetes Association (ADA) and the European Association for the Study of Diabetes (EASD). Diabetes Care. 2012;35(6):1364-79.

3. Davis TM, Davis Cyllene Uwa Edu Au WA, Bruce DG. Glycaemic levels triggering intensification of therapy in type 2 diabetes in the community: the Fremantle Diabetes Study. Med J Aust. 2006;184: 325-8.

4. Korytkowski M. When oral agents fail: practical barriers to starting insulin. Int J Obes Relat Metab Disord. 2002;26(Suppl 3):S18-24.

5. Ross SA, Tildesley HD, Ashkenas J. Barriers to effective insulin treatment: the persistence of poor glycemic control in type 2 diabetes. Curr Med Res Opin. 2011;27(Suppl 3):13-20.

6. Caputo S, Andersen H, Kaiser M, Karnieli E, Meneghini LF, Svendsen AL. Effect of baseline $\mathrm{HbA}_{1 \mathrm{c}}$ on glycemic control and diabetes management following initiation of once-daily 
insulin detemir in real-life clinical practice. Endocr Pract. 2013;21:1-32.

7. Philis-Tsimikas A. Tolerability, safety and adherence to treatment with insulin detemir injection in the treatment of type 2 diabetes. Patient Prefer Adherence. 2008;2(2):323-32.

8. Peterson GE. Analog insulin detemir for patients with type 1 and type 2 diabetes: a review. Diabetes Metab Syndr Obes. 2009;15(2):31-6.

9. Raslová K, Tamer SC, Clauson P, Karl D. Insulin detemir results in less weight gain than NPH insulin when used in basal-bolus therapy for type 2 diabetes mellitus, and this advantage increases with baseline body mass index. Clin Drug Investig. 2007;27(4):279-85.

10. Hermansen K, Davies M. Does insulin detemir have a role in reducing risk of insulin-associated weight gain? Diabetes Obes Metab. 2007;9(3):209-17.

11. Home $P$, Naggar NE, Khamseh $M$, et al. An observational non-interventional study of people with diabetes beginning or changed to insulin analogue therapy in non-Western countries: the $\mathrm{A}_{1}$ chieve study. Diabetes Res Clin Pract. 2011;94: 352-63.

12. Stumvoll M, Goldstein BJ, van Haeften TW. Type 2 diabetes: principles of pathogenesis and therapy. Lancet. 2005;365(9467):1333-46.

13. American Diabetes Association. Standards of medical care in diabetes-2013. Diabetes Care. 2013;36(Suppl 1):S11-66.

14. IDF Clinical Guidelines Task Force. Global guideline for type 2 diabetes. Brussels: International Diabetes Federation; 2012. Available online from http://www.idf.org/sites/default/files/ IDF-Guideline-for-Type-2-Diabetes.pdf. Accessed on 23 May 2013.

15. Opie LH, Yellon DM, Gersh BJ. Controversies in the cardiovascular management of type 2 diabetes. Heart. 2011;97:6-14.

16. Philis-Tsimikas A, Charpentier G, Clauson P, Ravn GM, Roberts VL, Thorsteinsson B. Comparison of once-daily insulin detemir with NPH insulin added to a regimen of oral antidiabetic drugs in poorly controlled type 2 diabetes. Clin Ther. 2006;28(10): 1569-81.

17. Rosenstock J, Davies M, Home PD, Larsen J, Koenen C, Schernthaner G. A randomised, 52-week, treatto-target trial comparing insulin detemir with insulin glargine when administered as add-on to glucose-lowering drugs in insulin-naive people with type 2 diabetes. Diabetologia. 2008;51(3):408-16.

18. Blonde L, Merilainen M, Karwe V, Raskin P. Patientdirected titration for achieving glycaemic goals using a once-daily basal insulin analogue: an assessment of two different fasting plasma glucose targets-the TITRATE study. Diabetes Obes Metab. 2009;11(6):623-31.

19. Hermansen K, Davies M, Derezinski T, Martinez Ravn G, Clauson P, Home P. A 26-week, randomized, parallel, treat-to-target trial comparing insulin detemir with NPH insulin as add-on therapy to oral glucose-lowering drugs in insulin-naive people with type 2 diabetes. Diabetes Care. 2006;29:1269-74.

20. Selam JL, Koenen C, Weng W, Meneghini L. Improving glycemic control with insulin detemir using the 303 Algorithm in insulin naïve patients with type 2 diabetes: a subgroup analysis of the US PREDICTIVE 303 study. Curr Med Res Opin. 2008;24(1):11-20.

21. Saydah SH, Fradkin J, Cowie CC. Poor control of risk factors for vascular disease among adults with previously diagnosed diabetes. JAMA. 2004;291: 335-42.

22. Bangalore S, Kumar S, Lobach I, Messerli FH. Blood pressure targets in subjects with type 2 diabetes mellitus/impaired fasting glucose: observations from traditional and bayesian random-effects meta-analyses of randomized trials. Circulation. 2011;123(24):2799-810 (9 p following 810).

23. Peyrot $M$, Rubin RR, Lauritzen $T$, International DAWN Advisory Panel, et al. Resistance to insulin therapy among patients and providers: results of the cross-national Diabetes Attitudes, Wishes, and Needs (DAWN) study. Diabetes Care. 2005;28(11): 2673-9. 